\title{
The potential role of 'Candidatus Microthrix parvicella' in phosphorus removal during sludge bulking in two full-scale enhanced biological phosphorus removal plants
}

\author{
Juan Wang, Rong Qi, Miaomiao Liu, Qian Li, Haipeng Bao, Yaming Li, \\ Shen Wang, Valter Tandoi and Min Yang
}

\begin{abstract}
We investigated the bacterial community compositions and phosphorus removal performance under sludge bulking and non-bulking conditions in two biological wastewater treatment systems (conventional $\mathrm{A}^{2} / \mathrm{O}$ (anaerobic/anoxic/aerobic) and inverted $\mathrm{A}^{2} / \mathrm{O}$ (anoxic/anaerobic/aerobic) processes) receiving the same raw wastewater. Sludge bulking resulted in significant shift in bacterial compositions from Proteobacteria dominance to Actinobacteria dominance, characterized by the significant presence of filamentous 'Candidatus Microthrix parvicella'. Quantitative real-time polymerase chain reaction (PCR) analysis revealed that the relative abundance of 'Candidatus Accumulibacter phosphatis', a key polyphosphate-accumulating organism responsible for phosphorus removal, with respect to 16s rRNA genes of total bacteria was 0.8 and $0.7 \%$, respectively, for the conventional and inverted $\mathrm{A}^{2} / \mathrm{O}$ systems when sludge bulking occurred, which increased to 8.2 and $12.3 \%$ during the non-bulking period. However, the total phosphorus removal performance during the bulking period (2-week average: $97 \pm 1$ and $96 \pm 1 \%$, respectively) was not adversely affected comparable to that during the non-bulking period (2-week average: $96 \pm 1$ and $96 \pm 1 \%$, respectively). Neisser staining revealed the presence of large polyphosphate granules in 'Candidatus Microthrix parvicella', suggesting that this microbial group might have been responsible for phosphorus removal during the sludge bulking period when 'Candidatus Accumulibacter phosphatis' was excluded from the systems.

Key words | bacterial community, 'Candidatus Microthrix parvicella', EBPR, phosphorus removal,

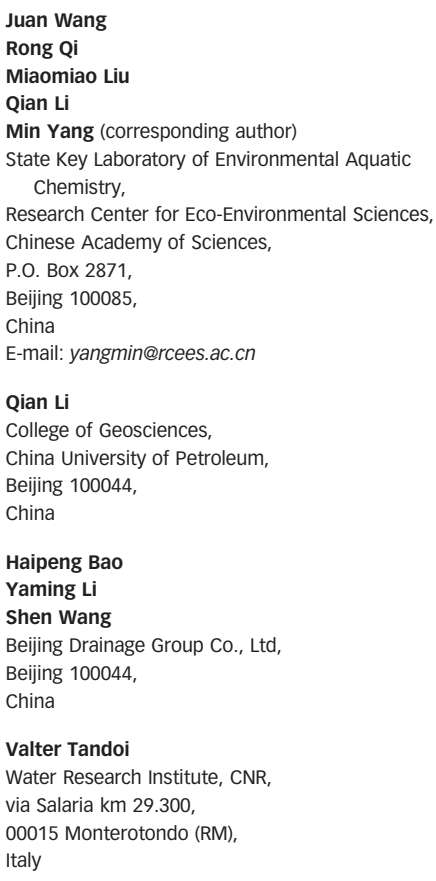
sludge bulking

\section{INTRODUCTION}

Bacterial communities in activated sludge are mainly responsible for the removal of pollutants, including phosphorus and nitrogen compounds from wastewater, and thus represent the core component in wastewater treatment systems. The enhanced biological phosphorus removal (EBPR) process is achieved by enrichment of polyphosphate-accumulating organisms (PAOs) under alternating anaerobic-aerobic conditions (Crocetti et al. 2000). A large amount of research efforts have been made to identify the microorganisms responsible for EBPR. Based on classical culture-dependent methods, early studies have speculated that Acinetobacter spp. may be responsible for
EBPR because they were routinely isolated from EBPR sludge (Oehmen et al. 2007). However, later studies using cultivation-independent molecular techniques showed that Acinetobacter is not primarily responsible for EBPR (He et al. 2006). Further investigations led to the identification of bacteria phylogenetically affiliated with the Rhodocyclus group of the Betaproteobacteria as candidate PAOs, which is a coccobacillus with a tentatively proposed name ' $\mathrm{Candi-}$ datus Accumulibacter phosphatis' (He et al. 2006). In a previous study, a strong positive correlation was established between the proportion of 'Candidatus Accumulibacter phosphatis' and the phosphorus content in activated 
sludge in laboratory-scale reactors (Oehmen et al. 2007), which was supported by a survey carried out in six EBPR plants in Australia (Saunders et al. 2003). Previous studies have shown that the relative abundance of 'Candidatus Accumulibacter phosphatis' to total bacteria could be in a range of 4-22\% (Oehmen et al. 2007), indicating that it is an important organism contributing to phosphorus removal in EBPR plants. Recently, members of the genus Tetrasphaera have been considered to be other putative PAOs in EBPR from wastewater (Kristiansen et al. 20I3).

Sludge bulking, which adversely affects sludge settleability in the secondary clarifiers as well as effluent quality, frequently occurs in EBPR systems. The overgrowth of filamentous bacteria has been considered to be mainly responsible for sludge bulking, and one of the most frequently encountered filamentous bacteria is 'Candidatus Microthrix parvicella' (Rossetti et al. 2005). With a low maximum specific growth rate, high storage capacities, and low maintenance energy requirements, 'Candidatus Microthrix parvicella' has a significant advantage over other microorganisms prevailing in the extended aeration activated sludge systems under starvation conditions. When serious sludge bulking occurs, outgrowth of filamentous bacteria, including 'Candidatus Microthrix parvicella', could lead to the exclusion of functional bacteria like 'Candidatus Accumulibacter phosphatis', which may adversely affect the phosphorus removal performance. The storage of polyphosphates has been speculated as a survival strategy for 'Candidatus Microthrix parvicella' (Erhart et al. I997). Machnicka (2006) has revealed that 'Candidatus Microthrix parvicella' might be responsible for the phosphorus removal in a laboratory-scale experiment. However, it has never been revealed if 'Candidatus Microthrix parvicella' could act as a PAO for phosphorus removal when 'Candidatus Accumulibacter phosphatis' is excluded from the systems during the sludge bulking period in a full-scale EBPR system.

In this study, the phosphorus removal performance of two parallel full-scale municipal wastewater treatment systems in a plant located in Beijing, China, which have been experiencing serious sludge bulking mainly caused by 'Candidatus Microthrix parvicella' in winter time, was continuously monitored over a period of 12 months to determine the potential impacts of sludge bulking on EBPR. The bacterial community structures as well as the abundance of 'Candidatus Accumulibacter phosphatis' under sludge bulking conditions were compared with those under non-bulking conditions. The knowledge acquired in this study will contribute towards better management of the EBPR systems.

\section{MATERIALS AND METHODS}

\section{Description of the wastewater treatment plant}

The investigated municipal wastewater treatment plant consists of a conventional $\mathrm{A}^{2} / \mathrm{O}$ system (anaerobic/anoxic/ aerobic) and an inverted $\mathrm{A}^{2} / \mathrm{O}$ system (anoxic/anaerobic/ aerobic) (Figure S1, available online at http://www. iwaponline.com/wst/070/216.pdf), each of which has a treatment design capacity of $200,000 \mathrm{~m}^{3} /$ day. Since the two systems were fed with the same sewage, one system could be used as the reference for another system. The sludge recycling ratio was approximately 100\% for both the systems, while the mixed liquor recirculation ratio was $250 \%$ for the conventional system and none for the inverted one. In the inverted system, the influent was distributed into the anoxic and anaerobic tanks, respectively, at a ratio of $7: 3$. In the past 3 years, each system had received mean wastewater flows of $225,000 \mathrm{~m}^{3} /$ day. The two systems had exhibited sludge bulking from late December to early May, with the inverted $\mathrm{A}^{2} / \mathrm{O}$ system exhibiting more serious bulking. Beijing is characterized with a relatively cold winter. The low temperature might be responsible for the occurrence of sludge bulking (Rossetti et al. 2005). The proliferation of 'Candidatus Microthrix parvicella' in the mixed liquor may be caused by the increased availability of the hydrophobic substrates such as lipids at low temperature (Xie et al. 2007). When 'Candidatus Microthrix parvicella' grows in sufficient numbers in activated sludge, it can also cause foaming problem in two systems. Sludge bulking disappeared from mid-May when the temperature was above $20^{\circ} \mathrm{C}$. The operating conditions, including hydraulic residence times and sludge retention times (SRTs), are summarized in Table 1. The 2009 performance data were kindly provided by the plant operators. The determination of biochemical oxygen demand (BOD), chemical oxygen

Table 1 | Major parameters of the conventional and inverted $\mathrm{A}^{2} / \mathrm{O}$ systems

\begin{tabular}{lll} 
Parameter & $\begin{array}{l}\text { Conventional } \mathbf{A}^{\mathbf{2} / \mathbf{O}} \\
\text { system }\end{array}$ & $\begin{array}{l}\text { Inverted } \mathbf{A}^{\mathbf{2}} \mathbf{0} \\
\text { system }\end{array}$ \\
\hline Q (ton/day) & 225000 & 225000 \\
MLSS (mg/L) & $3516-4499$ & $3002-4446$ \\
SRT (day) & $14.2 \pm 7.0$ & $9.3 \pm 5.8$ \\
F/M (kg BOD/(kg MLSS·day)) & $0.12 \pm 0.05$ & $0.19 \pm 0.09$ \\
$\begin{array}{l}\text { Influent distribution in } \\
\quad \text { anoxic/anaerobic } \\
\text { reactors }\end{array}$ & $/$ & $7: 3$ \\
\hline
\end{tabular}

MLSS: mixed liquor suspended solids; F/M: food to microorganism ratio. 
demand (COD), total phosphorus and soluble orthophosphate concentrations was performed by plant according to Standard Methods of Water and Wastewater Monitoring (2002). We have detected the soluble orthophosphate concentrations in different sections in the sampling days, as shown in Table S2 (available online at http://www. iwaponline.com/wst/070/216.pdf).

As shown in Figure S2 (available online at http://www. iwaponline.com/wst/070/216.pdf), the total phosphorus removal performance for the two systems was in general good except for some occasional fluctuations. The effluent total phosphorus and soluble orthophosphate concentrations over the whole year were $0.1-0.4 \mathrm{mg} / \mathrm{L}$ and $0.02-$ $0.11 \mathrm{mg} / \mathrm{L}$ for the conventional and inverted $\mathrm{A}^{2} / \mathrm{O}$ systems, respectively. The reasons for the fluctuations of phosphorus removals were not clear, but may relate to the fluctuations of the influent loading conditions. Two-week average values for each sampling time (day 76 to 90 (D76-D90) in the bulking period and D176-D190 in the non-bulking period) were used for evaluating the performance of the two systems during bulking and non-bulking periods, and are shown in Table 2.

\section{Activated sludge samples and DNA extraction}

In total, four activated sludge samples were taken from the ends of the aerobic units of the two systems: two in March (D83) when sludge bulking occurred (sludge volume index $(\mathrm{SVI})=189$ and $216 \mathrm{~mL} / \mathrm{g}$ for the conventional and inverted $\mathrm{A}^{2} / \mathrm{O}$ systems, respectively) and the other two in July (D183) when the systems returned to the normal state $(\mathrm{SVI}=73$ and $79 \mathrm{~mL} / \mathrm{g}$, respectively). The samples were centrifuged at $10,000 \mathrm{rpm}$ for $10 \mathrm{~min}$ at $4{ }^{\circ} \mathrm{C}$, and $0.25 \mathrm{~g}$ (wet weight) of activated sludge was used for DNA extraction, carried out using a FastDNA SPIN kit for soil (MP Biomedicals,
USA) in accordance with the instructions provided by the manufacturer. The final volumes of the DNA solutions were $50 \mu \mathrm{L}$. Triplet genomic DNA was extracted from these samples and then pooled.

\section{Cloning and sequencing of 16s rRNA genes}

The 16sRNA gene fragments were amplified by polymerase chain reaction (PCR) using primer pairs $27 f\left(5^{\prime}\right.$-AGA GTT TGA TCC TGG CTC AG-3') and 1492r (5'-TAC GGY TAC CTT GTT ACG ACT T-3') (Martin-Laurent et al. 20oI) for bacteria. The conditions for PCR amplification were as follows: initial $95^{\circ} \mathrm{C}$ for $10 \mathrm{~min}$, followed by 35 cycles of $95^{\circ} \mathrm{C}$ for $60 \mathrm{~s}, 55^{\circ} \mathrm{C}$ for $60 \mathrm{~s}$, and $72^{\circ} \mathrm{C}$ for $90 \mathrm{~s}$, with a final extension step of $10 \mathrm{~min}$ at $72{ }^{\circ} \mathrm{C}$. The PCR products were purified using a TIANpure Mini Plasmid kit (Tiangen, China). The 16s rRNA amplicons were cloned into TOPO TA cloning vector pCR2.1, with TOP10 Escherichia coli transformants further selected according to the manufacturer's instruction (Invitrogen, China). The transformants were selected by blue-white selection on Luria-Bertani agar plates containing ampicillin $(100 \mu \mathrm{g} / \mathrm{mL})$. The cloned inserts were amplified from lysed colonies by PCR with plasmid-vector-specific primers M13F (5'-GTA AAA CGA CGG CCA G-3') and M13R (5'-CAG GAA ACA GCT ATG AC-3'). Positive clones were sequenced with an ABI 3730 automated sequencer (Invitrogen, Shanghai, China).

\section{Phylogenetic analysis}

After editing and trimming manually using BioEdit, the bacterial 16s rRNA gene sequences were searched against the GenBank database using BLASTN (Altschul et al. 1997). The most similar reference sequences were downloaded and aligned with the sequences of the present study using ClustalX

Table 2 | Performances of the conventional and inverted $A^{2} / 0$ systems

\begin{tabular}{|c|c|c|c|c|c|c|}
\hline & \multicolumn{3}{|c|}{ Conventional $A^{2} / 0$ system } & \multicolumn{3}{|c|}{ Inverted $A^{2} / 0$ system } \\
\hline & $\begin{array}{l}\text { Sludge } \\
\text { bulking }\end{array}$ & $\begin{array}{l}\text { Non-sludge } \\
\text { bulking }^{\mathrm{a}}\end{array}$ & $\begin{array}{l}\text { Statistical } \\
\text { significance }^{b}\end{array}$ & $\begin{array}{l}\text { Sludge } \\
\text { bulkinga }\end{array}$ & $\begin{array}{l}\text { Non-sludge } \\
\text { bulking }^{\mathrm{a}}\end{array}$ & $\begin{array}{l}\text { Statistical } \\
\text { significance }^{b}\end{array}$ \\
\hline BOD removal efficiency & $(97 \pm 1) \%$ & $(97 \pm 1) \%$ & $P>0.05$ & $(97 \pm 1) \%$ & $(96 \pm 1) \%$ & $P>0.05$ \\
\hline COD removal efficiency & $(93 \pm 1) \%$ & $(94 \pm 1) \%$ & $P>0.05$ & $(92 \pm 2) \%$ & $(92 \pm 2) \%$ & $P>0.05$ \\
\hline $\begin{array}{l}\text { Total phosphorus removal } \\
\text { efficiency }\end{array}$ & $(97 \pm 1) \%$ & $(96 \pm 1) \%$ & $P<0.05$ & $(96 \pm 1) \%$ & $(96 \pm 1) \%$ & $P>0.05$ \\
\hline $\begin{array}{l}\text { Soluble orthophosphate removal } \\
\text { efficiency }\end{array}$ & $(98 \pm 1) \%$ & $(97 \pm 1) \%$ & $P>0.05$ & $(98 \pm 2) \%$ & $(98 \pm 1) \%$ & $P>0.05$ \\
\hline
\end{tabular}

a 2-week average related to sludge sampling.

baired-samples $t$-test was used to assess the significant differences in the efficiencies between different sludge states based on $P$-values 
(Thompson et al. 1997). Four 16s rRNA gene libraries were constructed (AAB and $\mathrm{AAN}$, bacteria in bulking and non-bulking sludge from the conventional $\mathrm{A}^{2} / \mathrm{O}$ system; IAB and IAN, bacteria in bulking and non-bulking sludge from the inverted $\mathrm{A}^{2} /$ O system). The operational taxonomic unit (OTU)_number was determined using mothur software by defining the sequences sharing $97 \%$ or greater similarity as one OTU (Schloss \& Handelsman 2005). The sequences obtained in the present study were deposited in the NCBI GenBank under accession number KF427922-KF428121.

\section{Quantification of total bacteria and 'Candidatus Accumulibacter phosphatis' using quantitative real- time PCR}

Quantitative real-time PCR was performed to quantify the 16s rRNA genes of total bacteria and 'Candidatus Accumulibacter phosphatis' using primer sets 341f/534r (Koike et al. 2007) and PAO651f/PAO846r (Fukushima et al. 2007), respectively. Standard plasmids carrying the target genes were obtained by utilizing TA clones and extracted using a TIANpure Mini Plasmid kit (Tiangen, China). The concentrations of the standard plasmids $(n g / \mu \mathrm{L})$ were determined with NanoDrop ND-1000 (NanoDrop, USA), and their copy concentrations (copies $/ \mu \mathrm{L}$ ) were subsequently calculated by using the following formula (Pei et al. 2006):

copy concentration (copies $/ \mu \mathrm{L}$ )

$$
=\frac{\text { DNA mass concentration }(\mathrm{ng} / \mu \mathrm{L})}{\text { DNA molecular weight }(\mathrm{g} / \mathrm{mol})} \times 6.02 \times 10^{23} \times 10^{-9}
$$

Triplicate quantitative real-time PCR assays were performed for the decimally diluted standard plasmids to obtain the standard curves, with no amplification signal from the negative control. Duplicate assays were performed for all samples on an ABI7300 apparatus (ABI, USA) using SYBR Green chemistry, as described previously (Fukushima et al. 2007). The following requirement was satisfied to obtain reliable quantification: $R^{2}=0.99$ for standard curves over five orders of magnitude. The specificity was assured by melting curves and gel electrophoresis. The gene copies per gram wet weight are shown in Table S2. To minimize the variance caused by the differences in bacterial abundance as well as DNA extraction and quantification efficiencies, the relative abundance of 'Candidatus Accumulibacter phosphatis' was obtained by normalizing their copy numbers to those of the 16s rRNA genes.

\section{Microscopic examination, filament identification and Neisser staining}

Microscopic observations of filamentous bacteria were under contrast at $\times 100$ or $\times 1000$ magnification, using an Olympus BX51 microscope, and the micrographs of sludge samples were taken via a charge-coupled device camera connected to the microscope. The determination of abundance and dominance of filamentous bacteria and Neisser staining for polyphosphate determination were carried out according to Jenkins et al. (2004). Filament abundance was observed at $100 \times$ magnification and subjectively rated for overall abundance on a scale from 0 (none) to 6 (excessive). In all samples, the microscopical examinations were conducted independently by three observers to confirm the scoring of filament abundance.

\section{Statistical analysis}

The similarities and diversities in bacterial compositions between bulking and non-bulking sludge samples were determined using mothur software (Schloss et al. 2009). All other statistical analyses were performed using the SPSS software, version 18.0.

\section{$\overline{\text { RESULTS AND DISCUSSION }}$}

\section{Performance of the two systems}

SVI value of $150 \mathrm{~mL} / \mathrm{g}$ has been considered as the starting point of sludge bulking (Lau et al. I984; Liao et al. 2004). The microscopic examination of bulking sludge samples (SVI $=189$ and $216 \mathrm{~mL} / \mathrm{g}$ for the conventional and inverted $\mathrm{A}^{2} / \mathrm{O}$ systems, respectively) showed that the floc structures were weak and diffuse (Figure S3, available online at http://www.iwaponline.com/wst/070/216.pdf). The scoring of filamentous abundance was 5 (abundant). The morphology of non-bulking sludge samples $(\mathrm{SVI}=73$ and $79 \mathrm{~mL} / \mathrm{g}$, respectively) was different from bulking sludge samples. The floc structure became firm and compact. The scoring of filamentous abundance decreased to 2 (some).

Table 2 shows the average removals of BOD, COD, total phosphorus and soluble orthophosphate under sludge bulking (D76-D90) and non-bulking (D176-D190) conditions. The BOD and COD removals were almost the same for both sludge bulking and non-bulking conditions. In general, the total average phosphorus and soluble orthophosphate removal efficiencies were at a level of $96 \%$ and $97 \%$, 
respectively, over the whole year, except for occasional disturbances. The total phosphorus and soluble orthophosphate removals during the sludge bulking period (2-week average: $97 \pm 1$ and $96 \pm 1 \%$, respectively; $98 \pm 1$ and $98 \pm 2 \%$, respectively) were comparable to those during the non-bulking period (2-week average: $96 \pm 1$ and $96 \pm 1 \%$, respectively; $97 \pm 1 \%$ and $98 \pm 1 \%$, respectively), showing that the system performance in terms of BOD, COD, and phosphorus removals was not adversely affected by the occurrence of sludge bulking.

\section{Bacterial community structures under different settleability conditions}

The four 16s rRNA gene libraries were constructed as shown in Figure 1 and Table S1 (available online at http://www. iwaponline.com/wst/070/216.pdf). A total of 21 and 49 OTUs were obtained for the sludge bulking (AAB; SVI = $189 \mathrm{~mL} / \mathrm{g}$ ) and non-bulking (AAN; SVI $=73 \mathrm{~mL} / \mathrm{g}$ ) bacterial libraries of the conventional $\mathrm{A}^{2} / \mathrm{O}$ system, respectively, and 16 and 46 OTUs were obtained for the sludge bulking (IAB; SVI $=216 \mathrm{~mL} / \mathrm{g}$ ) and non-bulking (IAN; SVI $=79 \mathrm{~mL} / \mathrm{g}$ ) bacterial libraries of the inverted $\mathrm{A}^{2} / \mathrm{O}$ system. A significant decrease in the OTU number for the sludge bulking clone libraries of both the systems implied that a reduction in the diversity was accompanied by the occurrence of sludge bulking. Meanwhile, cluster analysis revealed that the bacterial communities under non-bulking conditions clearly differed from those under bulking conditions (Figure 2).

In the present study, the two bulking sludge samples exhibited a significantly low biodiversity (Shannon index of 2.20 and 2.10 for AAB and IAB libraries, respectively).

\begin{tabular}{|c|c|c|c|}
\hline$\square$ Actinobacteria & $\square$ Gammaproteobacteria & $\square$ Betaproteobacteria & $\square$ Alphaproteobacteria \\
\hline$\square$ Deltaproteobacteria & $\square$ Firmicutes & Bacteroidetes & $\square$ Chloroflexi \\
\hline Acidobacteria & 回Planctonycetes & $\square$ Nitrospirae & $\square$ Unclassified \\
\hline
\end{tabular}
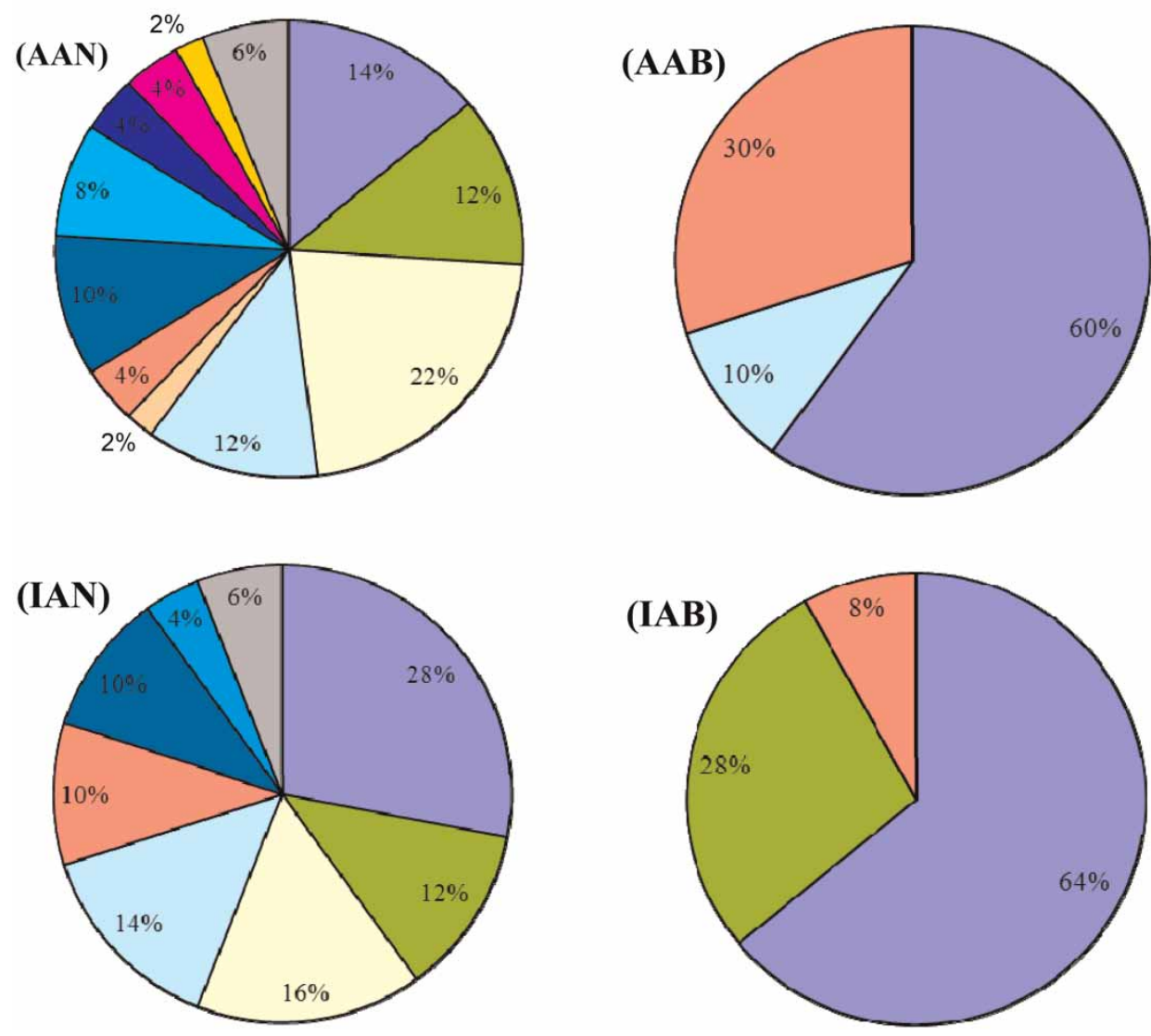

Figure 1 Abundance distribution of bacteria in $A^{2} / O$ and inverted $A^{2} / O$ systems. (AAN) Conventional $A^{2} / O$ system during non-bulking period; (AAB) conventional $A^{2} / O$ system during sludge bulking period; (IAN) inverted $A^{2} / O$ system during non-bulking period; (IAB) inverted $A^{2} / O$ system during sludge bulking period. 


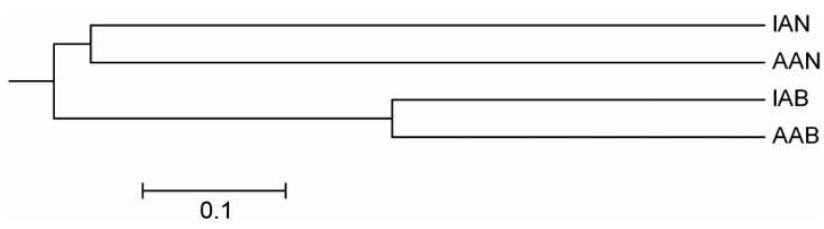

Figure 2 | Dendrograms of similarity (based on the membership-based Jaccard coefficient calculated using Chao1 estimated richness values) between bulking sludge and non-bulking samples for conventional and inverted $\mathrm{A}^{2} / \mathrm{O}$ systems, respectively, based on cluster analysis of bacterial composition using mothur. The scale bar indicates linkage distance for the index.

It is possible that the excessive growth of 'Candidatus Microthrix parvicella' in the mixed liquor led to the de-flocculation of activated sludge, resulting in the washout of the non-filamentous bacteria. The bacterial clones affiliated with the phylum Actinobacteria constituted the vast majority ( 60 and $66 \%$ ), followed by the clones affiliated with the phyla Firmicutes (30 and 8\%) and Proteobacteria (10 and 26\%). Furthermore, 50 and 60\% clones affiliated with Actinobacteria in the AAB and IAB libraries, respectively, were related to filamentous 'Candidatus Microthrix parvicella' (GenBank Accession No. JQ624332), and this finding was in accordance with the microscopic observation (Figure 3). The higher ratio of clones related to 'Candidatus Microthrix parvicella' in the inverted $\mathrm{A}^{2} / \mathrm{O}$ system was in accordance with the higher SVI value $(216 \mathrm{~mL} / \mathrm{g}$ vs. $189 \mathrm{~mL} / \mathrm{g}$ in the conventional $\mathrm{A}^{2} / \mathrm{O}$ system). Firmicutes was the second most abundant group followed by Alphaproteobacteria in the AAB library while Gammaproteobacteria followed by Firmicutes were present in the IAB library. The organisms related with phylum Firmicutes are usually found involved in pollutant degradation (Hesham et al. 20II). Some Alphaproteobacteria and Gammaproteobacteria isolated from the activated sludge had been identified as denitrifies (Nielsen et al. 20Ioa). However, the differences of bacterial community structures between $\mathrm{AAB}$ and $\mathrm{IAB}$ were not very clear.

On the other hand, the two non-bulking clone libraries exhibited a high similarity and diversity (Shannon indices of 3.88 and 3.59 for AAN and IAN, respectively) in bacterial community composition. The dominant bacteria were affiliated with the phylum Proteobacteria (48 and $42 \%$ for AAN and IAN libraries, respectively), primarily comprising the classes Betaproteobacteria (22 and 16\%), Gammaproteobacteria (12 and 12\%), and Alphaproteobacteria (12 and 14\%). The phylum Actinobacteria was the second largest group (14 and 28\%), followed by the phyla Bacteroidetes (10 and 10\%), Firmicutes (4 and 10\%), and Chloroflexi (8 and $4 \%$ ). The bacterial compositions of the conventional and inverted $\mathrm{A}^{2} / \mathrm{O}$ processes were found to be in accordance with those reported in previous studies, showing that microbial populations in EBPR plants are rather similar (Nielsen et al. 20Iob). Thus, it was clear that sludge bulking resulted in drastic shift in bacterial compositions from Proteobacteria dominance to Actinobacteria dominance.

In an EBPR process, 'Candidatus Accumulibacter phosphatis' and, occasionally, Tetrasphaera spp. are known to be the principal PAOs (Kristiansen et al. 2013). Crocetti et al. (2000) and Hesselmann et al. (1999) demonstrated that 'Candidatus Accumulibacter phosphatis' corresponded to the characteristic PAO phenotype of anaerobic/aerobic cycling of polyphosphate and poly- $\beta$-hydroxyalkanoates (PHAs). PAOs can take up carbon sources such as volatile fatty acids (VFAs) under anaerobic conditions, and store them intracellularly as PHAs. In the present study, no clone

(a)

(b)

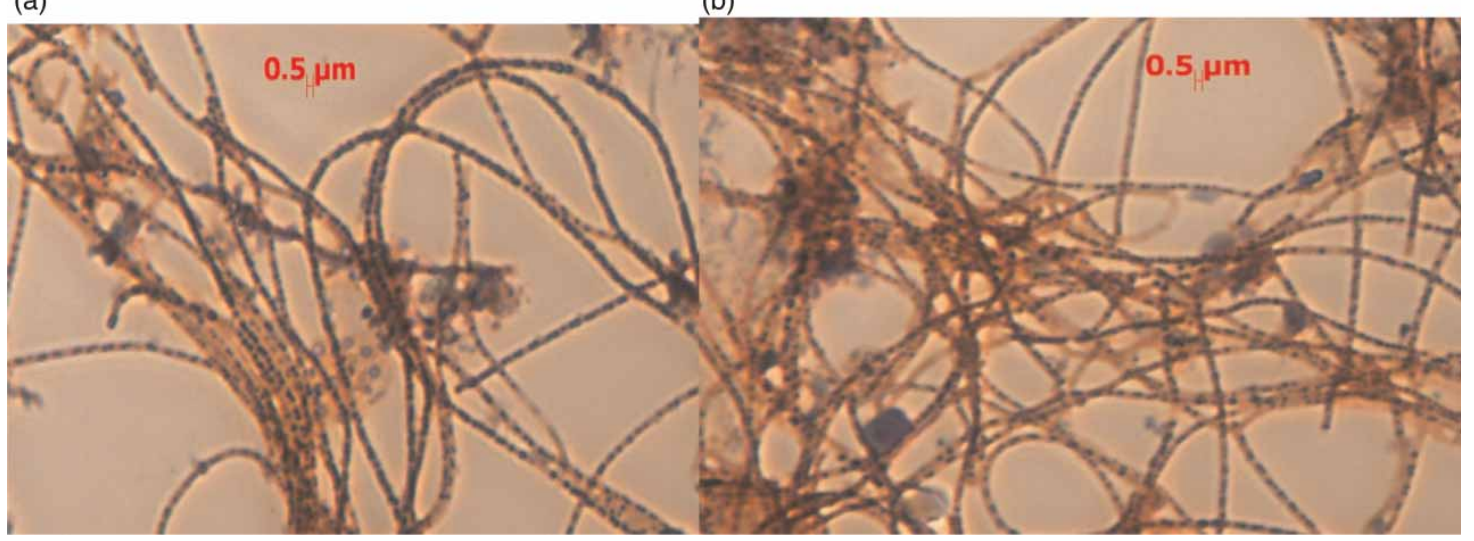

Figure 3 | Neisser-stained dark-colored (blue-back in online version of paper available at http:www.iwaponline.com/wst/toc.htm) polyphosphate granules in 'Candidatus Microthrix parvicella' (1000x) during sludge bulking period ('Candidatus Microthrix parvicella' is the bacterium showing large polyphosphate granules accumulation). (a) Conventional $A^{2} / O$ system; (b) inverted $A^{2} / O$ system. 
related to Tetrasphaera spp. was noted, and one OTU (one clone) closely related to 'Candidatus Accumulibacter phosphatis' was observed in the IAN library. As will be discussed in the next section, the 'Candidatus Accumulibacter phosphatis' with respect to $16 \mathrm{~s}$ rRNA genes of total bacteria were 8.2 and $12.3 \%$, respectively, for the conventional and inverted $\mathrm{A}^{2} / \mathrm{O}$ systems during $\mathrm{n}=$ the non-sludge bulking period. So it was possible that 'Candidatus Accumulibacter phosphatis' was the main PAO for both systems under non-sludge bulking condition. One possible explanation for the low detection ratios of 'Candidatus Accumulibacter phosphatis' in clone libraries might be the bias caused by PCR (Becker et al. 200o).

\section{Abundances of 'Candidatus Microthrix parvicella' and PAOs under sludge bulking and non-bulking conditions}

Quantitative real-time PCR was used to quantify the 'Candidatus Accumulibacter phosphatis' population (Table S3, available online at http://www.iwaponline.com/wst/070/ 216.pdf). When sludge bulking occurred, the relative abundance was $0.8 \%$ and $0.7 \%$, respectively, for the conventional and inverted $\mathrm{A}^{2} / \mathrm{O}$ systems, which was extremely low in comparison with previous studies for full-scale EBPR systems (4.4-24\% by using the quantitative real-time PCR method and 4-22\% by using the fluorescence in-situ hybridization (FISH) technique) (He et al. 2007). However, as shown in Table 2, Table S2 and Figure S2, the total phosphorus and soluble orthophosphate removals were 96-97\% and 98\%, respectively, for the conventional and inverted $\mathrm{A}^{2} / \mathrm{O}$ systems during the bulking period, showing that the phosphorus removal performance was not adversely affected by the significant reduction of the 'Candidatus Accumulibacter phosphatis' population. Thus, the 'Candidatus Accumulibacter phosphatis' population should not be the major PAOs responsible for the phosphorus removal during sludge bulking.

On the other hand, the 'Candidatus Accumulibacter phosphatis' with respect to $16 \mathrm{~s}$ rRNA genes of total bacteria increased to 8.2 and $12.3 \%$, respectively, for the conventional and inverted $\mathrm{A}^{2} / \mathrm{O}$ systems during the non-sludge bulking period. The ratios of the 'Candidatus Accumulibacter phosphatis' population in the two systems were in accordance with previous full plant investigations (Oehmen et al. 2007). Thus, the 'Candidatus Accumulibacter phosphatis' population should be the major PAOs responsible for the phosphorus removal during the non-bulking period.

Then what might be the main bacterial population, instead of 'Candidatus Accumulibacter phosphatis', responsible for the phosphorus removal during the sludge bulking period? Neisser staining has been used to confirm the presence of polyphosphate inclusions in the microbial components of activated sludge (Eikelboom \& Van Buijsen I98I). As shown in Figure 3, dark-colored (blue-black in online version of paper) polyphosphate globules (Eikelboom 2000) were observed mainly in 'Candidatus Microthrix parvicella', confirming the presence of large polyphosphate granules in this filamentous bacterium. The ability of ' $\mathrm{Candi-}$ datus Microthrix parvicella' to produce polyphosphate inclusion has also been reported (Eikelboom \& Van Buijsen I98I; Rossetti et al. 2005). Machnicka (2006) found that 'Candidatus Microthrix parvicella' had the capacity for distinct phosphorus removal from wastewater in a laboratory-scale experiment. Erhart et al. speculated that the storage of polyphosphate might be a survival strategy for the 'Candidatus Microthrix parvicella' population in response to cell stress (Erhart et al. 1997; Kristiansen et al. 2013). The anaerobic zone in phosphate removal plants could impose a stressful condition for 'Candidatus Microthrix parvicella', and induce this organism to store polyphosphate (Erhart et al. I997). Furthermore, the presence of genes encoding a polyphosphate glucokinase (EC 2.7.1.63) and a polyphosphate/ ATP NAD+ (nicotinamide adenine dinucleotide) kinase (EC 2.7.1.23) has been found in 'Candidatus Microthrix parvicella' strain RN1, suggesting the possible role of polyphosphate in direct phosphorylation of intermediates involved in energy metabolism (Kristiansen et al. 20I3). The hindrance for its study was due to the difficulties with its isolation and cultivation, and its characteristic slow growth. Future studies are required to clarify the potential role of 'Candidatus Microthrix parvicella' in phosphorus removal.

\section{CONCLUSION}

The bacterial community structures as well as the abundance of 'Candidatus Accumulibacter phosphatis' in two parallel full-scale municipal wastewater treatment systems under sludge bulking conditions were compared with those under non-bulking conditions. Sludge bulking resulted in significant shift in bacterial compositions from Proteobacteria dominance to Actinobacteria dominance, characterized by the significant presence of filamentous 'Candidatus Microthrix parvicella' and decrease in the 'Candidatus Accumulibacter phosphatis' population. However, the phosphorus removal efficiency was not adversely affected by the significant loss of the 'Candidatus Accumulibacter phosphatis', which should have played a key role in phosphorus removal. These results suggested 
that 'Candidatus Microthrix parvicella' might be responsible for phosphorus removal during sludge bulking.

\section{ACKNOWLEDGEMENTS}

This work was financially supported by the National Natural Science Foundation of China (grant nos 51378489 and 31170468). We are grateful for the Free Exchange Programs between the Chinese Academy of Science and the Italian National Research Council.

\section{REFERENCES}

Altschul, S. F., Madden, T. L., Schaffer, A. A., Zhang, J., Zhang, Z., Miller, W. \& Lipman, D. J. I997 Gapped BLAST and PSIBLAST: a new generation of protein database search programs. Nucleic Acids Research 25 (17), 3389-3402.

Becker, S., Böger, P., Oehlmann, R. \& Ernst, A. 2000 PCR bias in ecological analysis: a case study for quantitative Taq nuclease assays in analyses of microbial communities. Applied and Environmental Microbiology 66 (11), 4945-4953.

Crocetti, G. R., Hugenholtz, P., Bond, P. L., Schuler, A., Keller, J., Jenkins, D. \& Blackall, L. L. 2000 Identification of polyphosphate-accumulating organisms and design of $16 \mathrm{~S}$ rRNA-directed probes for their detection and quantitation. Applied and Environmental Microbiology 66 (3), 11751182.

Eikelboom, D. H. 2000 Process Control of Activated Sludge Plants by Microscopic Investigation. International Water Association, London, UK.

Eikelboom, D. \& Van Buijsen, H. I98I Microscopic Sludge Investigation Manual. TNO Research Institute for Environmental Hygiene Water and Soil Division, Delft, The Netherlands, Report A 94.

Erhart, R., Bradford, D., Seviour, R. J., Amann, R. \& Blackall, L. L. I997 Development and use of fluorescent in situ hybridization probes for the detection and identification of 'Microthrix parvicella' in activated sludge. Systematic and Applied Microbiology 20 (2), 310-318.

Fukushima, T., Uda, N., Onuki, M., Satoh, H. \& Mino, T. 2007 Development of the quantitative PCR method for Candidatus 'Accumulibacter phosphatis' and its application to activated sludge. Journal of Water and Environment Technology 5 (1), 37-43.

He, S., Gu, A. \& McMahon, K. 2006 Fine-scale differences between Accumulibacter-like bacteria in enhanced biological phosphorus removal activated sludge. Water Science and Technology 54 (1), 111-118.

He, S., Gall, D. L. \& McMahon, K. D. 2007 'Candidatus Accumulibacter' population structure in enhanced biological phosphorus removal sludges as revealed by polyphosphate kinase genes. Applied and Environmental Microbiology $\mathbf{7 3}$ (18), 5865-5874.
Hesham, A. E.-L., Qi, R. \& Yang, M. 2om Comparison of bacterial community structures in two systems of a sewage treatment plant using PCR-DGGE analysis. Journal of Environmental Sciences 23 (12), 2049-2054.

Hesselmann, R. P., Werlen, C., Hahn, D., van der Meer, J. R. \& Zehnder, A. J. 1999 Enrichment, phylogenetic analysis and detection of a bacterium that performs enhanced biological phosphate removal in activated sludge. Systematic and Applied Microbiology 22 (3), 454-465.

Jenkins, D., Richard, M. G. \& Daigger, G. T. 2004 Manual on the Causes and Control of Activated Sludge Bulking, Foaming, and Other Solids Separation Problems. IWA Publishing, London, UK.

Koike, S., Krapac, I. G., Oliver, H. D., Yannarell, A. C., CheeSanford, J. C., Aminov, R. I. \& Mackie, R. I. 2007 Monitoring and source tracking of tetracycline resistance genes in lagoons and groundwater adjacent to swine production facilities over a 3-year period. Applied and Environmental Microbiology 73 (15), 4813-4823.

Kristiansen, R., Nguyen, H. T., Saunders, A. M., Nielsen, J. L., Wimmer, R., Le, V. Q., McIlroy, S. J., Petrovski, S., Seviour, R. J., Calteau, A., Nielsen, K. L. \& Nielsen, P. H. 2013 A metabolic model for members of the genus Tetrasphaera involved in enhanced biological phosphorus removal. ISMEJ 7 (3), 543-554.

Lau, A. O., Strom, P. F. \& Jenkins, D. 1984 The competitive growth of floc-forming and filamentous bacteria: a model for activated sludge bulking. Journal (Water Pollution Control Federation) 56 (1), 52-61.

Liao, J., Lou, I. \& de los Reyes 3rd, F. L. 2004 Relationship of species-specific filament levels to filamentous bulking in activated sludge. Applied and Environmental Microbiology 70 (4), 2420-2428.

Machnicka, A. 2006 Accumulation of phosphorus by filamentous microorganisms. Pol. J. Environ. Stud. 15 (6), 947-953.

Martin-Laurent, F., Philippot, L., Hallet, S., Chaussod, R., Germon, J. C., Soulas, G. \& Catroux, G. 200I DNA extraction from soils: Old bias for new microbial diversity analysis methods. Applied and Environmental Microbiology 67 (5), 2354-2359.

Nielsen, P. H., Mielczarek, A. T., Kragelund, C., Nielsen, J. L., Saunders, A. M., Kong, Y., Hansen, A. A. \& Vollertsen, J. 20Ioa A conceptual ecosystem model of microbial communities in enhanced biological phosphorus removal plants. Water Research 44 (17), 5070-5088.

Nielsen, P. H., Mielczarek, A. T., Kragelund, C., Nielsen, J. L., Saunders, A. M., Kong, Y., Hansen, A. A. \& Vollertsen, J. 2orob A conceptual ecosystem model of microbial communities in enhanced biological phosphorus removal plants. Water Research 44 (17), 5070-5088.

Oehmen, A., Lemos, P. C., Carvalho, G., Yuan, Z., Keller, J., Blackall, L. L. \& Reis, M. A. 2007 Advances in enhanced biological phosphorus removal: from micro to macro scale. Water Research 41 (11), 2271-2300.

Pei, R., Kim, S. C., Carlson, K. H. \& Pruden, A. 2006 Effect of river landscape on the sediment concentrations of antibiotics and corresponding antibiotic resistance genes (ARG). Water Research 40 (12), 2427-2435. 
Rossetti, S., Tomei, M. C., Nielsen, P. H. \& Tandoi, V. 2005 'Microthrix parvicella', a filamentous bacterium causing bulking and foaming in activated sludge systems: a review of current knowledge. FEMS Microbiology Reviews 29 (1), 49-64.

Saunders, A., Oehmen, A., Blackall, L., Yuan, Z. \& Keller, J. 2003 The effect of GAOs (glycogen accumulating organisms) on anaerobic carbon requirements in full-scale Australian EBPR (enhanced biological phosphorus removal) plants. Water Science and Technology 47 (11), 37-43.

Schloss, P. D. \& Handelsman, J. 2005 Introducing DOTUR, a computer program for defining operational taxonomic units and estimating species richness. Applied and Environmental Microbiology 71 (3), 1501-1506.

Schloss, P. D., Westcott, S. L., Ryabin, T., Hall, J. R., Hartmann, M., Hollister, E. B., Lesniewski, R. A., Oakley, B. B., Parks, D. H.
\& Robinson, C. J. 2009 Introducing mothur: open-source, platform-independent, community-supported software for describing and comparing microbial communities. Applied and Environmental Microbiology 75 (23), 7537-7541.

Standard Methods of Water and Wastewater Monitoring 2002 4th edn. State Environmental Protection Administration of Beijing, China.

Thompson, J. D., Gibson, T. J., Plewniak, F., Jeanmougin, F. \& Higgins, D. G. 1997 The CLUSTAL_X windows interface: flexible strategies for multiple sequence alignment aided by quality analysis tools. Nucleic Acids Research 25 (24), $4876-4882$.

Xie, B., Dai, X.-C. \& Xu, Y.-T. 2007 Cause and pre-alarm control of bulking and foaming by Microthrix parvicella - A case study in triple oxidation ditch at a wastewater treatment plant. Journal of Hazardous Materials 143 (1), 184-191.

First received 14 January 2014; accepted in revised form 22 April 2014. Available online 24 May 2014 